\title{
Covid-19 And Factors Affecting Vietnamese Students' Readiness For Digital Transformation
}

\author{
Huyen Pham Thi ${ }^{*} \quad$ Nhi Tran Que Long La Gia Doan Ha My Vu Tien Duc \\ Marketing Faculty, National Economics University, 207 Giai Phong Street, \\ Hai Ba Trung District, Hanoi 100000, Vietnam
}

\begin{abstract}
Education in Vietnam is trying to make use of the values of the digital technology revolution. As one of the eight key fields of National Digital Transformation, education needs to find ways to develop and take advantage of opportunities to be able to shape the future of society with high-quality human resources. As a huge challenge, the Covid-19 pandemic has quickly put pressure on the past predicted trends in education such as the "university of the future", but, from a positive viewpoint, it also brings a big opportunity for universities to make the transformation, from classic one to the new and trendy university - the digital one. The paper analyzes in-depth the factors affecting the readiness of Vietnamese students for digital transformation in the above context. The research model is built based on the Technology Acceptance Model (TAM) theory and corrects necessary variables. The results show that the impact of Covid-19, self-study ability and attitude are the factors that have the most influence on the willingness to shift the learning method towards digitization. According to the result, the authors will propose several recommendations on improving the readiness of Vietnamese students for the digital transformation of education and training. Thereby helping students change to adapt to learning activities when the pandemic appears, and know how to take advantage of digital transformation.
\end{abstract}

Keywords: digital transformation, Covid-19, awareness, attitude, self-study

DOI: $10.7176 / \mathrm{JEP} / 12-16-04$

Publication date:June $30^{\text {th }} 2021$

\section{Introduction}

The outbreak of the Covid-19 pandemic has put pressure on the education industry around the world. Until now, it is clear that the digital transformation truly brought innovation and solutions to the education industry. According to UNICEF data released on 3/3/2021, about 168 million students worldwide had to miss school for nearly 1 year; 14 countries closed their schools between March 2020 and February 2021 because of the Covid-19 pandemic. This has caused a disruption in all teaching and learning activities, pushing educational and training institutions to immediately devise methods to allow students to "stop going to school but not stop learning".

In response to the Covid-19 pandemic outbreak, the Ministry of Education and Training (MOET) in Vietnam issued Official Letter code 795 on March 13, 2020, directing the deployment of online training methods in educational institutions. As the pandemic continues to worsen, official dispatch code 988 dated March 23, 2020, was proposed to unify distance learning implementation and acknowledge accumulated learning results. As can be seen, the Covid-19 pandemic has put pressure on the education industry, while simultaneously providing a tremendous motivation for digital transformation. Education and training institutions have made the most of the chances presented by the Covid-19 pressure to become "universities of the future" - a predicted educational trend (Etzkowitz et al., 2000, Marshall, 2018). Simultaneously, it is necessary to take advantage of IR 4.0 to close the space and time gap, bringing Vietnamese education closer to the quality of international education.

To research the impact of Covid19 and the factors affecting the readiness of Vietnamese students for digital transformation in learning, the article was conducted through a survey of 913 students at many universities in Viet Nam. The authors will next propose some methods to capitalize on opportunities created by the Covid-19 pandemic and encourage digital transformation in higher education, assisting teachers and students in fast adapting to digital transformation.

\section{Literature review}

\subsection{Theoretical of Technology Acceptance Model}

In order to identify and analyze the factors affecting intention and habit of using technology, authors have mainly used the Theory of Technology Acceptance Model - TAM of Davis (1989). According to Davis (1989), two factors ('Perceived Usefulness' and 'Perceived Ease of Use') are influenced by extrinsic factors and it can be predicted the "Attitude" of students. Moreover, "Perceived Usefulness" is not only an external factor but also directly affected by "Perceived Ease of Use". "Attitude" and "Perceived Usefulness" themselves will also influence the intention to use technology in a particular context and thereby, predict the intention and habit of using the system. 
Figure 1: Theoretical of Technology Acceptance Model - TAM

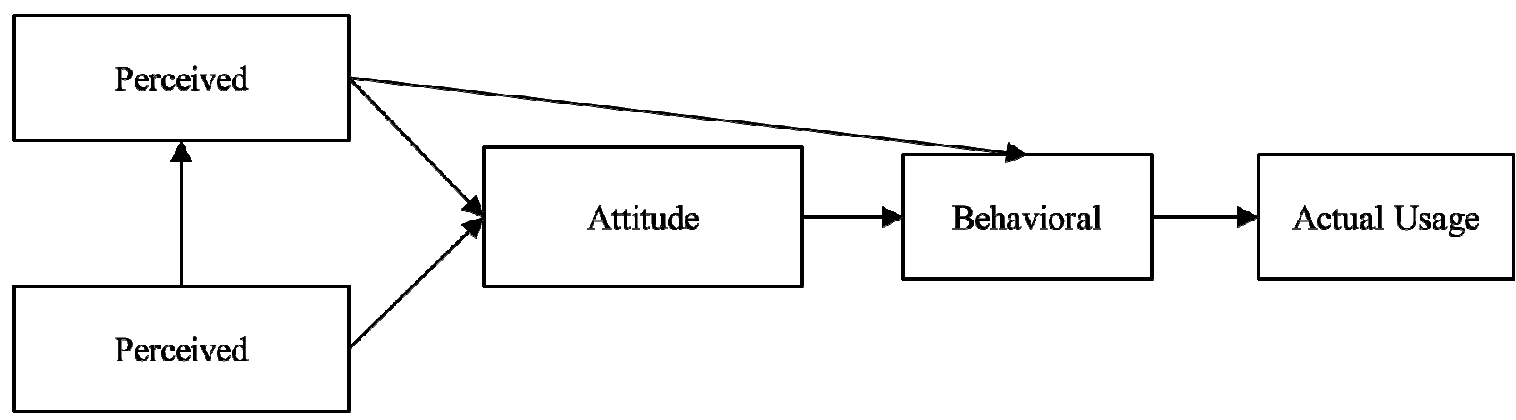

\subsection{Research model}

Previous studies have identified a variety of factors that can influence user behavior towards technology use. In terms of teaching and learning, Computer effectiveness (Chow et al., 2012), Social influence (Farahat, 2012), Feeling of enjoyment (Wu \& Gao, 2011), Computer anxiety (Alenezi et al., 2010), and Experience (Martin, 2012) are the factors affecting students' decision to use online learning systems that researchers have pointed out. These are considered extrinsic variables in Davis' extended TAM model (Abdullah and Ward, 2016) and are limited to TAM's core beliefs (i.e. Perceived Usefulness and Perceived Ease of Use). Although studies have demonstrated that external factors also play an important role in explaining technology adoption behavior, due to limited resources, the research team did not go into depth to assess the influence of these factors; our research focuses on the acceptance of technology application in student learning activities.

King and He (2006) after reviewing many studies, concluded that TAM is a perfectly suitable model to study the situation of accepting technology in learning. According to Šumak et al. (2011), TAM is the most popular theory in the research of technology and education, with $86 \%$ of the studies using TAM as the theoretical basis because this model provides the ability to solve problems. In the same opinion, Abdullah and Ward (2016) and Al-Qaysi (2018) believe that the application of the TAM model when researching technology acceptance in education and training will be more effective than other methods. Besides, through in-depth interviews and practical experiences, the research team found that students' acceptance of technology in learning is reflected in digital transformation and their willingness to change learning methods. Therefore, the team will use the TAM model as an important foundation theory and adjust the variables simultaneously to conduct research on learners' readiness for digital transformation in higher education.

Since then, we have built the research model and the following hypotheses:

Figure 2: Proposed research model

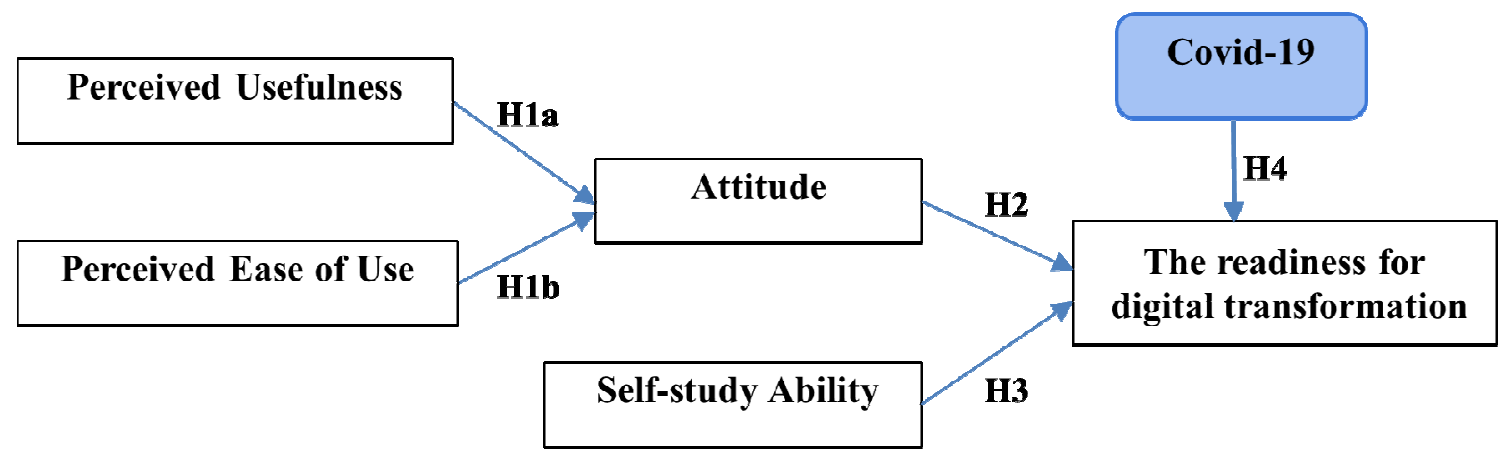

\subsection{Hypothesis}

2.3.1. Perceived Usefulness (PU) and Perceived Ease of Use (PEOU)

When researching on the behavior of using technology in learning, Moon and Kim (2001), Tarhini et al. (2013), Haryanto and Kaltsum (2016), and Salloum et al (2019) based on the TAM model to prove the positive relationship between Perceived Usefulness; Perceived Ease of Use and Attitude towards online learning. From there, the authors propose hypotheses:

H1a: Perceived Usefulness has a positive effect on students' attitudes towards digital transformation readiness.

H1b: Perceived Ease of Use has a positive effect on students' attitudes towards digital transformation readiness. 


\subsubsection{Attitudes (ATT)}

Fatema et al (2015); Chu \& Chen (2016) suggested that this attitude has a positive impact on students' acceptance of using online learning systems. The research of Salloum et al (2019) and Rizun \& Strzelecki (2020) also reinforced this statement. From there, the group proposed the hypothesis:

\section{H2: Attitudes towards online learning have a positive impact on students' digital transformation readiness}

2.3.3. Self-study Ability (SSA)

According to the results of in-depth interviews conducted by the team, when all learning and teaching activities are online, students' self-study ability also contributes to their readiness. According to Knowles (1976), "selfstudy" is a process in which learners, with or without the help of others, can identify their own learning needs, develop learning goals, select learning aids, effectively implement learning strategies, as well as evaluate their learning results. From there, they can work independently and cooperate with others (Trinh \& Rijlaarsdam, 2003). Simultaneously, Selim (2007) also suggested that the cooperation between learners can influence the use of the online learning system more. From there, the group proposed the hypothesis:

\section{H3: Self-study ability has a positive impact on students' readiness for digital transformation}

2.3.4. Covid-19

In theory, the Covid-19 epidemic taking place in Vietnam has no relation to the change in students' learning methods. However, the outbreak of this pandemic has caused both "teachers and students to quickly adapt", and "requires changes to adapt to learning without direct interaction". Is there a positive relationship between the Covid-19 epidemic and digital transformation in learning? Research hypothesis H4 is proposed based on testing the controlling role of the Covid-19 variable on students' intention to convert digitally. Hypothesis H4 is stated as follows:

\section{H4: Covid-19 had an impact on students' readiness for digital transformation}

\section{Research Methodology}

The authors created a research model and a draft scale based on theory and research overview. This draft scale system was calibrated using in-depth interviews with lecturers and students from various majors and universities. Following that, the authors designed the questionnaire, conducted a preliminary quantitative survey with 53 responses, and analyzed the Cronbach's Alpha reliability coefficient to ensure that the variables and scale were adequate for the research model. The official questionnaire is completed in order to conduct a formal quantitative survey with a sample size of 913 students currently enrolled in universities in Vietnam.

The data analysis revealed that both sexes participated in the study, with women accounting for the majority at a rate of $69.1 \%$. The majority of survey respondents live in cities $(78.4 \%)$. In fact, although students come from many regions, the proportion of individuals living, learning, and working in cities is frequently higher than in suburbs. Students from a variety of majors took part in the study as well. Students who participated in the poll studied Business and Management the most (54.3\%), followed by Humanities, Social Sciences and Behavior, Journalism, and National Defense, as well as students from Health, Mathematics and Statistics, Information Technology, Engineering, and other majors such as Education and Training, Life Science, Natural Science, Law,... The obtained data were coded and quantitatively analyzed to test the scale by Cronbach's Alpha analysis, exploratory factor analysis (EFA), confirmatory factor analysis (CFA), hypothesis testing, and effect assessment through running the Structural Equation Modeling technique.

\section{Research results}

\subsection{Cronbach's Alpha analysis}

Table 1: Results of verifying the reliability of the scale

\begin{tabular}{cccc}
\hline Factor & $\begin{array}{c}\text { Cronbach's Alpha } \\
\text { coefficient }\end{array}$ & $\begin{array}{c}\text { Cronbach's alpha if } \\
\text { item deleted }\end{array}$ & $\begin{array}{c}\text { Number of variables } \\
\text { removed }\end{array}$ \\
\hline Perceivable Usefulness (PU) & 0,824 & $0,706-0,826$ & $0 / 3$ \\
Perceivable Ease of Use (PEOU) & 0,887 & $0,804-0,865$ & $0 / 3$ \\
Attitude (ATT) & 0,894 & $0,846-0,886$ & $0 / 4$ \\
Self-study ability (SSA) & 0,788 & $0,653-0,756$ & $0 / 3$ \\
Readiness for digital transformation in & 0,912 & $0,882-0,910$ & $0 / 5$ \\
learning (CHANGE) & & &
\end{tabular}

Source: Summary of the research team's results, 2021

The reliability of the scale is assessed by Cronbach's Alpha analysis on the preliminary survey sample. The overall Cronbach's alpha coefficient is 0.912 and the Cronbach's Alpha if item deleted coefficient is in the range of 0.653 to 0.910 . The final results show that the value scales of the factor groups are reliable and the data correlation is consistent with the built scales. Then, the research team turned to EFA exploratory factor analysis to verify the convergence of the scale system of the factors in the model. 
4.2. Exploratory factor analysis (EFA) and confirmatory factor analysis (CFA)

4.2.1. Exploratory factor analysis result

Table 2: The results of exploratory factor analysis (EFA)

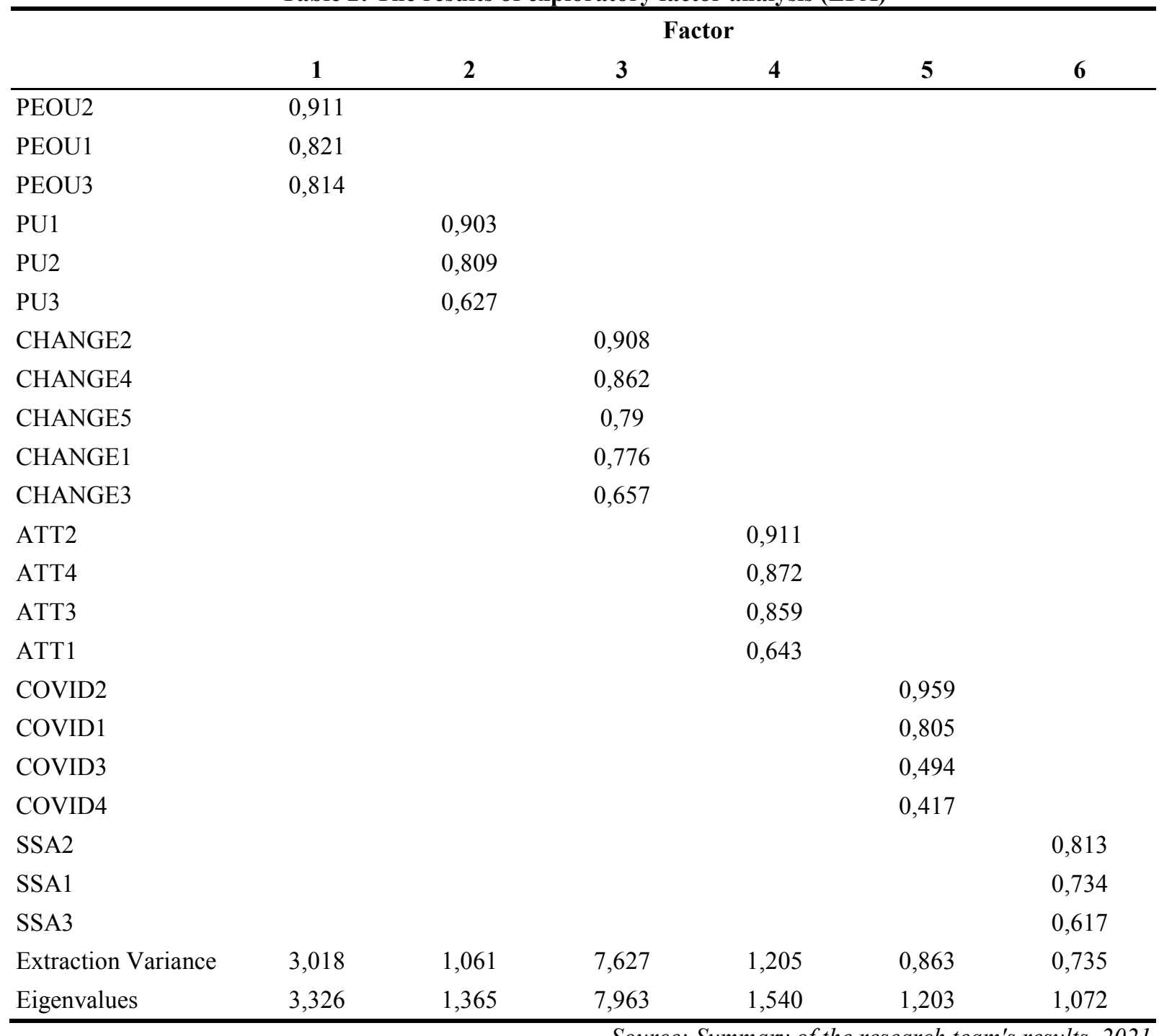

Source: Summary of the research team's results, 2021

Exploratory factor analysis (EFA) with a group of factors helps to assess the convergence and distinguish the value of the scale. Both KMO and Bartlett tests in EFA show that the hypothesis of correlation between variables can be accepted (Sig. $=0.000$ ). KMO coefficients of all factor groups are $>0.5$ (group of factors Awareness $=0.789$; group of 'Attitude, Self-study, Covid-19, Readiness level' $=0.923$ ) shows that EFA can be used. The analysis results show that at Eigenvalue $>=1$, with the "Principal Axis Factoring" method and the "Promax" rotation, there can be 6 factors extracted from 22 observed variables, and variance of the extraction of three groups factors is $67.99 \%$, respectively (PU, PEOU); 65.19\% (ATT, SSA, Covid-19, Readiness level for digital transformation) are $>50 \%$. The EFA test can be used for confirmatory factor analysis (CFA).

4.2.2. Confirmatory factor analysis results

To test the model's fit with market data, the research team performed a CFA analysis. The scale of the independent variables has been grouped into the following groups: "Perceived value" (PU), "Perceived ease of use" (PEOU), "Attitude" (ATT), "Self-study Ability" (SSA), is shown in the table 3: 
Table 3: Model Fit Rating Index

\begin{tabular}{ccc}
\hline & Index & Access \\
\hline CMIN/DF & 3,765 & Acceptable $(<5)$ \\
GFI & 0,945 & Good $(>0,9)$ \\
CFI & 0,970 & Good $(>0,9)$ \\
RMSEA & 0,055 & Good $(<0,06)$ \\
PCLOSE & 0,061 & Good $(>0,05)$ \\
\hline
\end{tabular}

Source: Summary of the research team's results, 2021

The above results show that Chi-square $/ \mathrm{df}=3.765(<5), \mathrm{GFI}=0.945(>0.9), \mathrm{CFI}=0.970(>0.9)$ and $\mathrm{RMSEA}=$ $0.055(<0.06)$. Therefore, the model can fit the research data and can be used for the next steps of analysis.

\subsection{Structural Equation Modeling (SEM) analysis}

The research team used the Structural Equation Modeling (SEM) technique to analyze the multidimensional relationship between the dependent variable "Readiness for Digital Transformation" (CHA) and two independent variables in the model. The obtained results are shown in the figure 3:

Figure 3: SEM results with the model without control variables

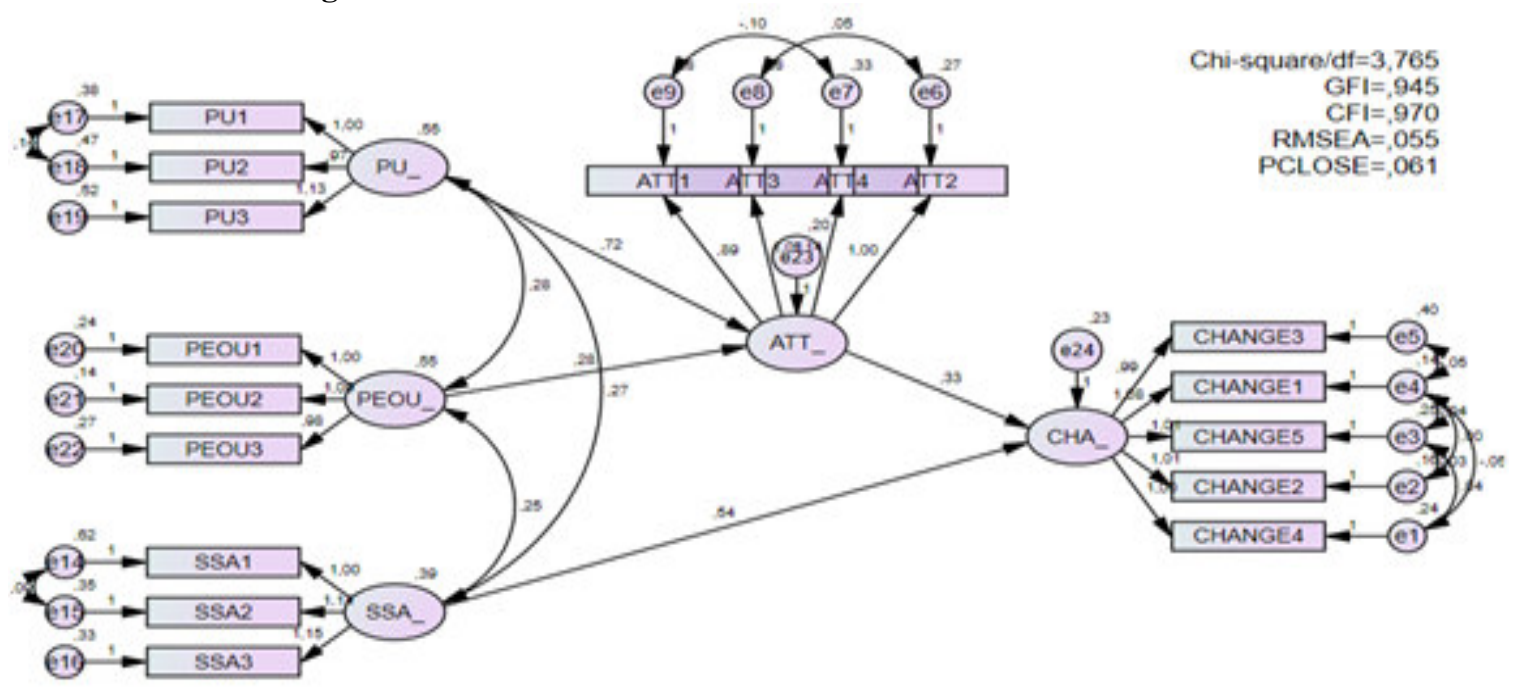

Source: Summary of the research team's results, 2021

It can be seen that two factors: "Attitude" and "Self-study Ability" both have a significant impact on the "Readiness of digital transformation" of students. The independent variables contributed $54.8 \%$ of the change of the dependent variable. In which, two factors "Perceived Ease of Use" and "Perceived usefulness" can predict $69.2 \%$ of the variation of "Attitude". The $\mathrm{P}$ index ( $\mathrm{sig}$ ) of the variables are all $<0.05$, reaching the $95 \%$ confidence level, so the relationships between the independent variables and the dependent variable are significant. Unstandardized regression weight shows the degree of impact of the independent variable on the dependent variable.

Table 4: Summary of test results

\begin{tabular}{ccccc}
\hline $\begin{array}{c}\text { Hypothesis } \\
\text { (Hs) }\end{array}$ & Regression weight & $\begin{array}{c}\text { P-Value } \\
\text { (Sig) }\end{array}$ & Result \\
\hline H1a & ATT <--- PU & 0,725 & 0,000 & Accepted \\
H1b & ATT <--- PEOU & 0,284 & 0,000 & Accepted \\
H2 & CHA <--- ATT & 0,329 & 0,000 & Accepted \\
H3 & CHA <--- SSA & 0,539 & 0,000 & Accepted \\
\hline
\end{tabular}

Source: Summary of the research team's results, 2021

The independent variable "Self-study ability" (SSA) has the greatest impact on the dependent variable "Readiness for Digital Transformation" (CHA), followed by the moderator variable "Attitude" (ATT). Thus, if students support, feel excited and proactive when learning online, the level of readiness for digital transformation in learning will be higher.

As the strongest influencing factor, the independent variable "Self-study ability" contributes to promoting the level of readiness for the digital transformation of Vietnamese students. So, if students actively participate in learning activities or interact with lecturers, students will be more ready for digital transformation. This can be explained by the fact that when Vietnamese students are more active in their learning, they will also actively adapt to changes in the context to make learning easier and more effective, thereby leading to an increase in the 
willingness to change learning behavior towards digitalization. Moreover, digital transformation, as mentioned in the context section, is inevitable in education. Therefore, if students have the desire to be proactive with their learning, they will also have the mentality of quickly adapting to the digital transformation in education, thus enhancing students' readiness for digital transformation. In addition, Selim (2007) also explained that the active cooperation and exchange among students can influence the use of the online learning system more, hence positively affecting their academic performance (Laily et al., 2013). As a result, this can be considered as a new factor discovered by the research team to strengthen and contribute to previous works.

Besides, the variable "Attitude" (ATT) is more strongly affected by the independent variable "Perceived usefulness" (PU) than "Perceived Ease of Use" (PEOU) when the unstandardized regression weights are 0.725 and 0.284 respectively. This result reinforces Park's (2009) study, which demonstrated that perceived usefulness has a statistically significant impact on attitudes toward a willingness to accept new learning methods. In addition, the influence of attitude on the intention to accept the behavior has been confirmed through the unstandardized regression weights of 0.309 and shows the similarity with the study of Park (2009) that used to do in Korea - an Asian country like Vietnam. As students' attitudes towards digital transformation education can shape behavior towards online learning and ultimately lead to learners' acceptance of it or not. This is completely reasonable in Vietnam, students find that using software and technology equipment does not require too much effort because they always use them competently to serve their study. exercise as well as other activities such as entertainment, work, connection,...

\subsection{Analyzing the impact of Covid19 on digital transformation readiness}

As a control variable in the SEM model, COVID-19 also affects the dependent variable "Readiness for digital transformation" (CHA) and makes the relationships between factors might change. The results obtained are shown in the figure and table as follows:

Figure 4: Normalized SEM results with control variable of COVID-19

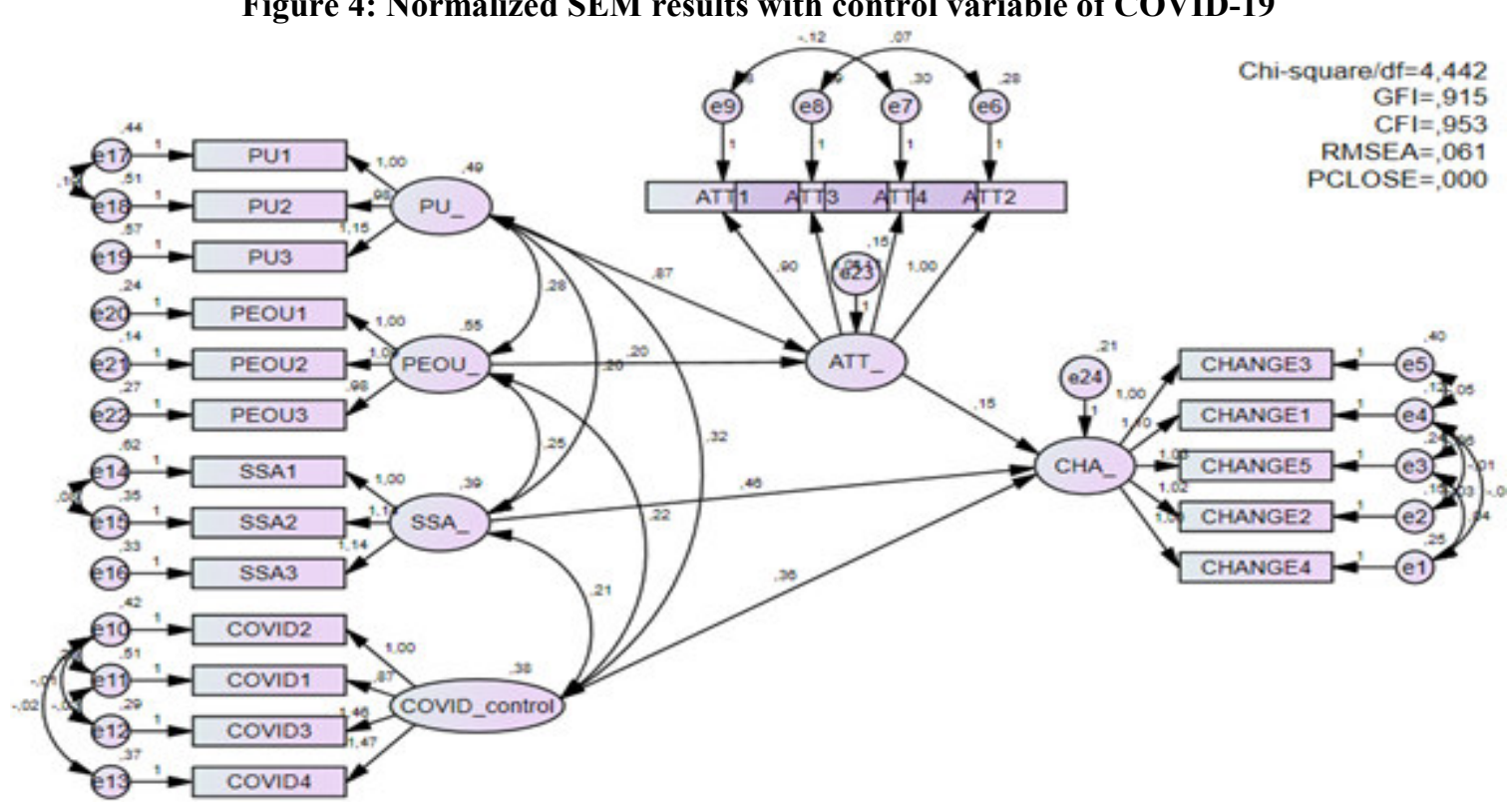

Source: Summary of the research team's results, 2021

The result showed that "Attitude" and "Self-study ability" still have a remarkable impact on the "Readiness for digital transformation" of Vietnamese students, control variable Covid-19 also contributes to this effect. The above three factors can explain up to $58 \%$ of the change of the dependent variable, higher than the SEM model analyzed in Section 4.3. In which, attitude can still be predicted by two variables "Perception of the value of online learning" and "Ease of doing online learning" with a squared multiple correlation index of 76, 9\%.

When Covid-19 is a control variable in the model, the P (Sig.) index of the hypotheses is still less than 0.05 , reaching 95\% reliability. Thus, the relationships of the independent variables and the control variable on the dependent variable are significant, the hypotheses H1a, H1b, H2, H3, H4 given with the SEM model have the appearance of Covid- 19 are all accepted. Table 5 below will compare the impact of the independent variables between the two SEM models by the regression coefficients (Regression Weights) that have been synthesized by the group through 2 times of analyses. 
Table 5: Comparison of two experimental models using the Regression Weights index

\begin{tabular}{|c|c|c|c|c|}
\hline $\begin{array}{l}\text { Hypothesis } \\
\text { (Hs) }\end{array}$ & $\begin{array}{l}\text { Without control variable } \\
\text { Covid-19 }\end{array}$ & $\begin{array}{l}\text { Regression } \\
\text { Weights }\end{array}$ & With control variable Covid-19 & $\begin{array}{c}\text { Regression } \\
\text { Weights }\end{array}$ \\
\hline H1a & $\mathrm{ATT} \leftarrow \mathrm{PU}$ & 0,725 & $\mathrm{ATT} \leftarrow \mathrm{PU}$ & 0,869 \\
\hline$H 1 b$ & $\mathrm{ATT} \leftarrow \mathrm{PEOU}$ & 0,284 & $\mathrm{ATT} \leftarrow \mathrm{PEOU}$ & 0,198 \\
\hline $\mathrm{H}^{2}$ & $\mathrm{CHA} \leftarrow \mathrm{ATT}$ & 0,329 & $\mathrm{CHA} \leftarrow \mathrm{ATT}$ & 0,151 \\
\hline H3 & $\mathrm{CHA} \leftarrow \mathrm{SSA}$ & 0,539 & $\mathrm{CHA} \leftarrow \mathrm{SSA}$ & 0,459 \\
\hline $\mathrm{H} 4$ & & & CHA $\leftarrow$ COVID_ctrl & 0,363 \\
\hline
\end{tabular}

Source: Summary of the research team's results, 2021

Through the SEM results with the presence of a control variable, authors found that the influence level of independent variables has changed even though the impact relationships are still positive. Self-study ability is still the factor that has the strongest impact on the dependent variable "Readiness for digital transformation" but the unstandardized regression index has decreased to $45.9 \%$. The control variable "Covid-19" now acts as the second strongest factor with $36.3 \%$ and the last variable is "Attitude" because the impact value has changed, which was reduced to only $15.1 \%$. At the same time, when Covid-19 appeared, the effect of "Perceived usefulness" on attitude increased significantly (86.9\%). Meanwhile, the influence of "Perceived ease of use" on attitude decreased very little with the unstandardized regression index of about $19.8 \%$.

Covid-19, the control variable in the research model has shown an important role as the second most influential factor, only after the factor belonging to the students - self-study ability. It is witnessed that the Covid-19 pandemic causes all education and training institutions to suspend all activities, online learning is considered the only solution for students to continue their learning activities. Universities have immediately pushed to implement distance education in order to keep teaching and learning activities (Barnes, 2020). However, besides the support from the unviersity and the lecturers, students themselves need to familiarize, adapt, and actively learn with devices, software, and technology platforms, and this is considered the clearest indication of readiness for digital transformation. In fact, the pandemic has made it impossible for students to have a second choice, if they are not willing to change their learning methods, students will not be able to guarantee learning outcomes. Moreover, after going through three waves of the epidemic, Vietnamese students have experienced, adapted, and verified the effectiveness of the blended-learning model, which is a combination of online and face-to-face learning. MOET (2020) has commented that: "The results of online teaching during the Covid-19 epidemic are evaluated well. However, it is still necessary to reorganize digital transformation activities in a more methodical way to improve efficiency". It can be affirmed that Covid-19 has made learners more aware of the role of online learning and also made them use more technology, integrate more tools and software in learning. Going through such a long process has motivated and made them more ready for this educational transition.

From the research results along with the education situation in Vietnam, the authors found that if Covid-19 continues to happen, under inevitable pressure, students will still be ready to change their learning methods. However, research by Burke and Dempsey 2020 has shown that there is still a high probability that there will be a group of students who may not continue their studies if they still have to study online. This means that closing schools can exacerbate the risk of educational disruption, where learners may pause their studies (Baker 2020). Therefore, schools need to have a clear orientation about the online curriculum so that teachers can continue to deliver instruction or guide learners in an appropriate, flexible, effective, and unrestricted manner (Onwusuru and Ogwo, 2019). Thereby helping students get the best learning experience, motivating them to be more ready for this digital transformation of teaching and learning.

\section{Conclusion on digital transformation opportunities in Vietnam higher education 5.1. Digital transformation in higher education is inevitable}

The world is witnessing dramatic changes in the digital age of Industry 4.0 and the far-reaching influence of science and technology on people's lives. These changes have had a comprehensive and profound impact on all areas of socio-economic life of countries. The goal of the current educational digital transformation is to train workers with enough knowledge and skills to respond to the rapid changes of society in order to avoid the risk of being fired. As a downstream training level, directly providing human resources for the labor market, only when the face of the education industry changes, universities, educational institutions, and training pioneers approach the job. Teaching and learning in a new way, making the most of technological advances and connected things, will be able to train quality human resources, keep pace with the needs of the market and meet the needs of the world. requirements of society. "The education sector is very interested in training Vietnamese citizens with digital transformation knowledge and skills to become global citizens. Doing well in digital transformation not only helps improve the quality of education but more importantly contributes to improving labor productivity, 
creating great opportunities for international integration" (Ministry of Education and Training, 2020). With such a goal, education will be one of the main pillars, effectively contributing to the success of the national digital transformation.

\subsection{Covid19 as a driver of digital transformation in higher education}

It is experienced that context is one of the most important factors when discussing this issue. The Covid-19 epidemic has made a great impact on the acceptance of online learning methods as well as the willingness of students to shift their learning behavior. The essence of Industrial Revolution 4.0 is the application of technology, data science, and the use of artificial intelligence for production and human life. IR 4.0 brings many favorable conditions to help people discover new sources of knowledge, improve the scale and quality of the economy. That is a prerequisite for the transition to online learning. The Covid-19 epidemic appeared, causing all activities to stop and paralyze, but Education and Learning must always continue to change to adapt, to keep pace with the development of technology that has always existed in the current context. Besides, the Covid19 pandemic also brings many opportunities for Vietnamese universities. Tran Thi Van Hoa et al (2020) says that one of the biggest opportunities that schools must know how to seize is to accelerate the application of digital technology in all school activities from teaching, scientific research to the digitization of learning materials and management information to progress towards building a "smart university". Many institutions have determined Covid-19 is an opportunity to promote the digitalization of materials so that all lecturers, students, and administrators can exploit the positive factors in the application of information technology in management, teaching, and learning activities; and can be flexible in time and space for teaching and learning. Covid-19 has opened up a new vision, helping Vietnam's education industry orientate to build the "University of the future", contributing to the national digital transformation.

\subsection{How to adapt to digital transformation in higher education}

\subsubsection{Universities and educational institutions}

Firstly, it is necessary to have the policy to train and guide managers and lecturers to help them have enough IT knowledge and skills to know how to teach in the digital environment. Simultaneously, universities need to enhance research activities to find the best online teaching methods to ensure the quality of teaching and learning. Secondly, education and training institutions need to promote communication activities so that students can be more aware of the online learning process and the values of the e-learning system. Thereby promoting students' awareness of learning to help them adapt to this new learning method and be more active in the learning process. Thirdly, it is recommended that universities should have specific plans on curricula, teaching and learning materials, etc. when universities implement online training methods. Simultaneously, universities should reduce procedures to avoid barriers for students to register for academic credits in the online learning process.

5.3.2. Lecturers

Firstly, lecturers need to actively use modern technology tools and apply new teaching methods to create an innovative and creative learning environment. This also contributes to strengthening students' consciousness, making them more aware of the usefulness of the online learning system. This is also the basis for creating excitement when learning according to the new learning method for students.

Secondly, lecturers should actively interact with students during online teaching. Specifically, they can ask questions for students to discuss, actively communicate and answer questions for students via email, LMS, etc. This will contribute to promoting awareness of students, thereby contributing to improving students' attitudes towards new learning methods.

5.3.3. Students

Firstly, students - the destination of transferred knowledge, skills, and experience: In order to achieve good learning efficiency in a learning environment that lacks face-to-face interaction, they need to have a sense of self-discipline during the online learning process. Students need to actively interact with lecturers through platforms and software such as Teams, Zoom, LMS, email, etc. to discuss, communicate and answer questions about learning content.

Secondly, with the ability to use technology well, students need to equip themselves for integrating skills of using tools such as Google Drive, Powerpoint, etc., and modern technology devices such as Ipad, laptop, notetaking applications electronic, etc. to support the learning process, making online learning more effective.

Thirdly, to be able to quickly catch up with new training methods, students need to know how to arrange and manage their schedule appropriately so that they can balance between study and personal activities when taking part in online learning.

\section{References}

Abdullah, F., \& Ward, R. (2016). Developing a General Extended Technology Acceptance Model for ELearning (GETAMEL) by analysing commonly used external factors. Computers in Human Behavior, 56, 
238-256. https://doi.org/10.1016/j.chb.2015.11.036

Alenezi, A. R., Abdul Karim, A. M., \& Veloo, A. (2010). An Empirical Investigation into the Role of Enjoyment, Computer Anxiety, Computer Self-Efficacy and Internet Experience in Influencing the Students' Intention to Use E-Learning: A Case Study from Saudi Arabian Governmental Universities. Turkish Online Journal of Educational Technology, 9(4), 22-34. Retrieved from https://eric.ed.gov/?id=EJ908069

Al-Qaysi, N., Mohamad-Nordin, N., \& Al-Emran, M. (2018). A Systematic Review of Social Media Acceptance From the Perspective of Educational and Information Systems Theories and Models. Journal of Educational Computing Research, 57(8), 2085-2109. https://doi.org/10.1177/0735633118817879

Barnes, S. J. (2020). Information management research and practice in the post-COVID-19 world. International Journal of Information Management, 55, 102175. https://doi.org/10.1016/j.ijinfomgt.2020.102175

Chow, M., Herold, D. K., Choo, T. M., \& Chan, K. (2012). Extending the technology acceptance model to explore the intention to use Second Life for enhancing healthcare education. Computers \& Education, 59(4), 1136-1144. https://doi.org/10.1016/j.compedu.2012.05.011

Davis, D. F.. (1989). Perceived Usefulness, Perceived Ease of Use, and User Acceptance of Information Technology. MIS Quarterly, 13(3), 319. https://doi.org/10.2307/249008

Etzkowitz, H., Webster, A., Gebhardt, C., \& Terra, B. R. C. (2000). The future of the university and the university of the future: evolution of ivory tower to entrepreneurial paradigm. Research Policy, 29(2), 313330. https://doi.org/10.1016/S0048-7333(99)00069-4

Farahat, T. (2012). Applying the Technology Acceptance Model to Online Learning in the Egyptian Universities. Procedia - Social and Behavioral Sciences, 64, 95-104. https://doi.org/10.1016/j.sbspro.2012.11.012

King, W. R., \& He, J. (2006). A meta-analysis of the technology acceptance model. Information \& Management, 43(6), 740-755. https://doi.org/10.1016/j.im.2006.05.003

Knowles, M. S. (1976). Autonomous learning. Cambridge: Cambridge Adult Education

Marshall, S. J (2018). Shaping the University of the Future: Using Technology to Catalyse Change in University Learning and Teaching. London: Springer. http://refhub.elsevier.com/S0268-4012(20)30995-6/sbref0085

Martin, R. (2012). Factors Affecting the Usefulness of Social Networking in e-Learning at German University of Technology in Oman. International Journal of E-Education, e-Business, e-Management and e-Learning, 2(6), 498-502. https://doi.org/10.7763/ijeeee.2012.v2.171

Onwusuru, M. I., \& Ogwo, B. A. (2019). Cloud-based portal for professional development of technology educators in Nigeria and the emerging virtual workplace. International Journal of Arts and Technology Education, 11(1), 1-17. Retrieved from https://www.researchgate.net/profile//jeomaOnwusuru/publication/339200734_UNN_INJA_Journal/links/5e54895992851c1dcb8b9b82/UNN-INJAJournal.pdf\#page $=10$

Šumak, B., Heričko, M., \& Pušnik, M. (2011). A meta-analysis of e-learning technology acceptance: The role of user types and e-learning technology types. Computers in Human Behavior, 27(6), 2067-2077. https://doi.org/10.1016/j.chb.2011.08.005

Hoa, T. T. V et al (2020), Covid-19 pandemic: Finding opportunities in challenges for Vietnamese universities in the new context. Journal of Economics and Development, 274, 64-74.

MOET (2020), Report of Online learning and teaching within the Covid-19: Situation and Solutions, National Conference for Online learning, Hanoi, Vietnam, May, 2020

Trinh, Q. L. \& Rijlaarsdam, G. (2003, September). An EFL curriculum for learner autonomy: design and effects. Paper presented at the conference Independent Language Learning, Melbourne: Australia.

UNICEF. (2021, March). United Nations Headquarters. Retrieved from https://www.unicef.org/pressreleases/schools-more-168-million-children-globally-have-been-completely-closed

UNESCO. (2020). Education: From disruption to recovery. Retrieved from https://en.unesco.org/covid19/educationresponse

Wu, X., \& Gao, Y. (2011). Applying The Extended Technology Acceptance Model To The Use Of Clickers In Student Learning: Some Evidence From Macroeconomics Classes. American Journal of Business Education (AJBE), 4(7), 43-50. https://doi.org/10.19030/ajbe.v4i7.4674 